\title{
Temporal and spatial estimates of adult mortality for small areas in Brazil, 1980-2010
}

\author{
Bernardo L. Queiroz \\ Universidade Federal de Minas Gerais \\ lanza@cedeplar.ufmg.br \\ Everton E.C. Lima \\ Universidade Estadual de Campinas \\ everton@ nepo.unicamp.br \\ Flávio H.M.A. Freire \\ Universidade Federal do Rio Grande do Norte \\ fhfreire@ccet.ufrn.br \\ Marcos R. Gonzaga \\ Universidade Federal do Rio Grande do Norte \\ marcosrg@ccet.ufrn.br
}

\section{Acknowledgments}

Project for mortality estimates and construction of life tables for small regions in Brazil (1980-2010) Ministry of Science, Technology, Innovation and Communications (MCTI)/National Council for Scientific and Technological Development (CNPq)/Ministry of Education (MEC)/ Brazilian Federal Agency for the Support and Evaluation of Graduate Education (CAPES)/Applied Social Sciences (Process No. 470866/2014-4) and MCTI/CNPq/Universal 14/2014 (Process No. 454223/2014-5).

\section{Contact:}

Av. Antonio Carlos, 6627 - Cedeplar/Face/UFMG, Belo Horizonte, MG - Brazil - 31270-901 - Ph: 55-31-3407-7100 


\section{BACKGROUND}

The study of mortality level and trends in developing countries is limited by the quality of vital registration system and population data, especially for small areas. However, understanding regional differences in data quality and mortality is crucial for public health planning.

\section{OBJECTIVE}

The paper aims to estimate adult mortality levels for small-areas in Brazil and to examine variations and spatial patterns of adult mortality across regions, overtime and by sex in the country

\section{METHODS}

We combine a three-method strategy. We apply a standardization technique to smooth rates in small areas. We then obtained measures of completeness of death counts coverage using Death Distribution Methods. And spatial analysis to investigate variations and patterns of adult mortality in small areas of the country.

\section{RESULTS}

We find that completeness of death counts coverage improved overtime across the country. We observed that regions in the south and southeast have complete death registration systems and areas in the less developed regions are improving. We observe a large and constant differential in adult mortality by sex and regions.

\section{CONCLUSIONS}

We find that the quality of mortality data in Brazil and regions is improving over time. The improvement is mostly explain by public investments in collection health data. Gender differences remained high over the period of analysis due to the increase in external causes of deaths for males. This increase also explains the concentration of high mortality levels for males in some areas of the country.

\section{CONTRIBUTION}

A new methodological procedure on estimating and analyzing the evolutions on adult mortality pattern over time and across smaller areas on the presence of defective data, on both vital statistics and population data.

Keywords: small areas, mortality estimation, demographic techniques, spatial analysis 


\section{Introduction}

In developing countries, knowledge of levels and trends of mortality are limited by the quality of data (AbouZhar and Boerma,2005). The most common problems faced in these countries are incomplete coverage of vital registration systems and errors in age declaration for both population and death counts (Luy, 2010; Setel et.al, 2007). In recent years, collection of data for death counts has improved, but there are still limitations for studying mortality in several parts of the world (AbouZahr et.al, 2015; Luy, 2010; Setel et.al, 2007). These limitations are even more striking in small areas of the country (Cavalini, et.al, 2007; França, et.al, 2008; Paes, 2005; Divino, Egidi and Salvatore, 2009; Tsimbos, Kalogirou and Verropoulou, 2014). The inability to produce proper estimates of mortality, especially in small areas, harms the development of public health policies and understanding the health transition in the country.

In this paper, we focus on analyzing the evolution of adult mortality, 45q15, in Brazil by sex and mesoregions from 1980 to 2010 . The main aims of this paper are to estimate adult mortality levels for small-areas in Brazil (mesoregions) and to examine variations and spatial patterns of adult mortality across regions, overtime and by sex in the country. We use mortality data from the Ministry of Health and population data from National Statistics Office and applied a combination of traditional demographic methods.

Small-areas mortality estimation and studies have gained relevance in recent years. Also, there is a large interest in regional mortality variation over time for a series of countries (Fenelon, 2013; Ram, et al, 2015; Ruther, Leyk and Buttenfield, 2017). For example, Kulkarni, et al. (2011) argue about the importance of regional mortality and health studies as guide points for the planning of public health policies and coverage of the health system. In their analysis, based on recent data from the United States, the authors show that there is a huge variability in life expectancy between locations, with some presenting mortality rates much higher than those observed in other developed 
countries. Similar research by Kibele, et al. (2015), in Germany, shows that the factors that explain mortality variation in the past are still affecting present regional mortality variation in the country. We can also argue that small areas in Brazil are, as the United States and Germany, characterized by mortality differentials, and there is an increasing demand for appropriate health policies, given the current aging process of the Brazilian population.

In Brazil, temporal and spatial analysis of adult mortality are limited by the quality of data (Queiroz, et.al, 2017; Borges, 2017; Gonzaga and Schemertman, 2016; Lima \& Queiroz, 2014; França, et.al, 2012; 2008; Paes, 2005; 2007). The most common problems faced are incomplete coverage of vital registration systems, errors in age declaration for both population and death counts, and lack of information on causes of deaths (Queiroz, et.al, 2017; Lima and Queiroz, 2014; Gonzaga and Schmmertman, 2016). If on one hand, there are many studies that describes variations of infant and child mortality in Brazil (Souza, Hill and Dal Poz, 2010; Barufi, Haddad and Paez, 2012; McKinnon, 2010), on the other hand, very little is known about spatiotemporal trends in adult mortality, and the overall quality of mortality data across country's regions. We argue that producing proper estimates of adult mortality for small areas in Brazil is very relevant for recent and future changes in life expectancy at birth might be more affected by variations in adult and old-age mortality. Recent studies show a convergence and decline in the levels of infant and child mortality (Souza, Hill and Dal Poz, 2010; Barufi, Haddad and Paez, 2012), but much less knowledge about mortality for older age groups.

In Brazil, even for some large areas on North and Northeast country and recent periods, mortality rates and life expectancy are estimated based on the infant and child mortality and using model life tables. In most cases, mortality age profile is construct from the information available on infant and child mortality from census or household surveys. However, vital registration systems and demographic methods allow one to produce estimates that do not need to use relational models and 
model life tables. In the case of Brazil, however, it is necessary to evaluate the quality of vital records, especially for the under-registration of death counts.

In addition, vital rates estimates in small areas are very limited and incipient due to the small risk population, resulting in a great challenge for demographers. This often happens due to the problem of few events recorded in the denominator and/or numerator of the measures of interest resulting in unstable estimates. Such instability is even worse when sub-national groups are disaggregated by age and sex (Gonzaga and Schmertmann, 2016; Assunção et al. 2005). Therefore, in small populations the estimated rates generally have extreme values leading to a large variability in the rates that do not reflect the true level of heterogeneity of the geographic location (Bernadinelli and Montomoli, 1992; Assunção et al., 2005).

This study is conducted threefold analyses. First, we propose a simple and replicable method to estimate adult mortality (45q15) for small areas in Brazil. We use a three-step approach: first, we apply an indirect standardization technique to smooth the mortality rates across age groups. Second, we applied the Death Distribution Methods (Hill, You and Choi, 2009) to estimate the undercount of deaths for all mesoregions. We adjust our small area estimates to the greater area, so that the total deaths observed in each state and the country match the added value from each small area. With the estimates in hand, we analyze the evolution on the adult mortality probabilities by sex and mesoregions in Brazil between 1980 and 2010 using spatial analysis methods. Public health administrators have large demand for small area estimates. This type of information can lead to better resource allocation and to evaluate the progress of social policy at the local level.

We find that the quality of mortality data in Brazil and regions is improving over time, a large part of the country shows almost complete coverage of death counts. The improvement is mostly explained by public investments in collection health data. Gender differences remained high over the 
period of analysis due to the increase in external causes of deaths for males. This increase also explains the concentration of high mortality levels for males in some areas of the country.

\section{Data and Methods}

\subsection{Brazilian Vital Registration and Population Data}

We make extensive use of the Ministry of Health database, DATASUS (http://www2.datasus.gov.br). The database provides information on deaths, causes of deaths, by age and sex at the municipality level. The data are available since 1979, but we use information from 1980 to 2010 . Mortality data is organized using codes from the ICD Revision (9th from 1980 to 1995 and $10^{\text {th }}$ from 1996 on). Data cleaning and compilation is done at the municipal, provincial and state level, and an electronic data file is transferred to the national office every 3 months. Population by age and sex, at the local level, comes from the Brazilian Censuses (1980, 1991, 2000 and 2010).

The original data is available at the municipality level. The main limitation in using city level data in Brazil is that the number and composition of cities change over time. In 1980, there were 3974 municipalities and in 2010 there were 5565 (Ehrl, 2017). To avoid problems using this information, we aggregated municipalities by comparable small areas, using the IBGE definition of comparable mesoregions. The mesoregions serve only for statistical purpose; therefore, they do not represent a political or administrative entity, but they share some socioeconomic similarities. The main advantage of working with these geographical areas is that they have not changed their boundaries over the period of analysis and they are areas with regional and socioeconomic similarities. Mesoregions are stable and comparable over the period of analysis, thus we can follow and study 137 small areas in Brazil from 1980 to 2010. 


\subsection{Methodology}

The analysis of adult mortality by space and time in Brazil is divided in different steps. Before analyzing levels, trends and spatial patterns of adult mortality in Brazil, we provide consistent estimates of adult mortality for 137 regions in Brazil. It is not possible to produce direct estimates because of incompleteness of death counts coverage in the country and other problems associated with small areas estimation. In the paper, the estimation of adult mortality is performed in three stages. We combine traditional demographic methods to obtain robust estimates of adult mortality. First, we use indirect standardization to smooth mortality age profiles and, then, apply death distribution methods to evaluate the quality of mortality data and obtain an adjustment factor for death counts under-coverage. We focus on adult mortality, $45 q 15$, as a synthetic measure of adult mortality for our analysis. We chose to use this measure for simplicity and comparability with other studies. We assume that the age of entry into adulthood can be defined at age 15. At that age, there is the turning point where declining childhood mortality risks are replaced by increased mortality risks for young adults and adults. In addition, this measure covers a substantive age range up to age 60 and avoids problems inherent in estimates of mortality at more advanced ages. With estimates available in hand we move on to analyze spatial-temporal evolution in adult mortality using traditional spatial analysis methods.

\subsubsection{Estimating Adult Mortality Rates}

\section{Step 1: Standardization}

We proposed a combination of standard demographic methods (Death Distribution Methods) with indirect standardization (Curtin and Klein, 1995) to estimate mortality levels by sex in mesoregions in Brazil. First, we standardize mortality rates from mesoregions (smaller areas), by sex, using state level data as standards. We estimate the standard death counts by age and sex as follows:

$$
D_{x, i}^{*}(t)=N_{x, i}(t) m_{x}(t)
$$


Where $D^{*}$ and $N$ represents, respectively, the expected number of deaths and observed population in each five-years age group at the mesoregion level in the census year $t ; m$ are the five-years agespecific mortality rates in the larger area (state) in the census year $t$. The subscripts $x$ and $i$ represents, respectively, 17 five-year age group (from 0 to $80+$ ) and 137 mesoregions. The calendar census years (t) are 1980, 1991, 2000 and 2010.

$D^{*}$ represents the expected number of deaths for each mesoregion $i$ under the assumption that the population by age in each mesoregion is exposed to the same age-specific mortality risk as observed in the larger area. However, by applying the equation (1) we standardized the pattern as well as the level of the mortality on each mesoregion, according to the lager area one. In order to keep the differences on level of mortality among mesoregions within a State, we calculate a factor to adjust the level of mortality for each mesoregion:

$$
\lambda_{i}=\frac{\sum_{x} D_{x, i}(t)}{\sum_{x} D_{x, i}^{*}(t)}
$$

$\lambda_{i}$ is the ratio (constant across age) between the total number of registered deaths and the total number of expected deaths for the mesoregion $i$. Then, we apply the factor $\lambda_{i}$ to the State's age-specific mortality rates to estimate the level of mortality for each mesoregion:

$$
m_{x, i}^{*}(t)=\lambda_{i} m_{x}(t)
$$

Based on the smoothed and standardized mortality rates obtained on equation (3), we reestimate the expected and standardized number of deaths by five years age group and mesoregions on each census year $t$ by:

$$
d_{x, i}^{*}(t)=N_{x, i}(t) m_{x, i}^{*}(t)
$$


Since the larger area's age-specific mortality rates are not unstable estimates this procedure eliminates the noise that occur due to small numbers of recorded deaths in the mesoregions, resulting in smoothed and standardized age-specific mortality rates on those small areas.

Finally, we used those expected and standardized number of deaths by five-year age group and mesoregions to calculate rates that incorporated the mortality risk for the entire period between two censuses:

$$
m_{x, i}^{*}(t, t+n)=\frac{\left[d_{x, i}^{*}(t)+d_{x, i}^{*}(t+n)\right] / 2}{\sqrt{N_{x, i}(t) N_{x, i}(t+n)}}
$$

where $n$ is number of years between two censuses.

The number of deaths obtained from Equation 5 does not solve the problems faced when studying mortality in developing countries. With this information, we move on to the second step, which involves estimating the completeness of death counts coverage and using the adjustment factor to obtain the expected corrected number of death counts and estimates of life-tables.

\section{Step 2: Death Distribution Methods}

We use Death Distribution Methods to obtain the expected number of deaths in the population. These methods evaluate coverage of deaths counts in relation to population counts (Hill, You and Choi, 2009). We present the methods briefly, because there is an extensive literature detailing its formalization (Benneth and Horiuchi, 1981; Hill, 1987; Hill, Choi and Timaeus, 2005; Hill, You and Choi, 2009; Dorrington et.al, 2014a; 2014b; Murray et al, 2010). These methods compare the age distribution of deaths with the age distribution of the population and provide the age pattern of mortality for a set period of time. There are three main methods: general growth balance (GGB), proposed by Hill (1987), synthetic extinct generations (SEG) proposed by Bennett and Horiuchi (1981), and the synthetic extinct generations adjusted (SEG-adj) proposed by Hill, You and Choi (2009). The deaths of distribution methods have strong assumptions: closed population, the degree 
of coverage of deaths is constant by age, the degree of population count has constant coverage by age and ages of living and deaths declared without errors. The advantage of these three methods over previous formulations Brass (1975), which is the flexibility of the stable population assumption.

The first method, GGB, is derived from the basic demographic balancing equation, which expresses the identity that the growth rate of the population is equal to the difference between its entry rate and exit rate. This identity holds for open-ended age segments $x+$, and in a closed population the only entries are through birthdays at age $x$. The "birthday" rate $x+$ minus the growth rate $x+$ thus provides a residual estimate of the death rate $x+$. If the residual estimate can be calculated from population data from two population censuses and compared to a direct estimate using the recorded deaths, the completeness of death recording relative to population recording can be estimated (Hill, 1987; Hill, Choi and Timaeus, 2005; Hill, You and Choi, 2009). Equation (6) presents the formalization of the GGB method:

$$
\frac{N^{\prime}(x)}{N(x+)}-r^{\prime}(x+)=\frac{1}{t} \ln \left(\frac{k_{1}}{k_{2}}\right)+\frac{\left(k_{1} k_{2}\right)^{1 / 2}}{C}\left(\frac{D^{\prime}(x+)}{N(x+)}\right)
$$

Where $N^{\prime}(x)$ is the number of persons who reach the exact age $x$ in the period, $N(x+)$ is the number of persons at exact age $x$ and over, $r(x+)$ is the population growth rate, $k_{1}$ and $k_{2}$ are the relative coverage of the enumerated population in two censuses, $C$ is the degree of completeness of death records over the period, $D^{\prime}(x+)$ is the observed number of deaths of people with $x$ or more years of age and $t$ is the interval corresponding to the intercensal period. Thus, the input rate minus the growth rate has a linear relationship with the mortality rate. From this equation, one can calculate, the degree of completeness of death records (C) over a period of time, and the relative coverage of the enumerated population in two censuses $\left(k_{1} / k_{2}\right)$. 
In other words, from the relationship between the input rate and the difference between the growth rate and mortality rate in every age group, it is possible to estimate a simple linear relationship that incorporates at the intercept any variation in coverage between the two censuses. And, we can also estimate a slope that serves as an indicator of the degree of coverage of the deaths of registration from the average coverage of both censuses.

The Bennett and Horiuchi method, SEG, (Benneth and Horiuchi, 1981) uses specific growth rates by age for converting an age distribution of deaths in an age distribution of a population. Once in a population the observed deaths from a given age $x$ is equal to the population of age $x$, adjusted by the rate of population growth by age range, we have the deaths of a population of age $x+$ that provide an estimate of the population on that age $x$. The extent of death registration coverage is given by the ratio of deaths estimated by the population above the age $x$ and the observed population above the age $x$. Equation (7) presents the mathematical formalization of the method:

$$
N^{\prime}(x)=\sum_{a=x}^{\omega} D(a) e^{[r(a-r)]}
$$

Where $N^{\prime}(x)$ is the number of people who reach the exact age $\mathrm{x}$ in a population with growth rate $r$, and $D(x)$ is the number of deaths at age $x$. In this case, the estimate of deaths under-registration in the period is given by the ration between the estimated number of people aged $x\left(N^{\prime}(x)\right)$ and the observed number of people aged $x(N(x))$.

Hill, You Choi (2009) suggest that the combination of the methods may be more robust than the application of two methods separately. The adjusted method consists of applying GGB to obtain estimates of the change in the population enumeration $\left(k_{1} / k_{2}\right)$, and use this ratio to adjust the coverage of both census, and then apply the SEG method using the adjusted population for the coverage of mortality data. There is an alternative to adjust the estimates proposed by Dorrington, since the differences in the final estimates are very small we opt to use the alternative proposed by Hill, You and Choi (2009). 
We use the three methods using alternative age ranges to evaluate the results. We opt to show the estimates based on the average of the three methods applied to the data. The estimates were produced using the R-package DDM (https://cran.r-project.org/package=DDM).

\section{Step 3: Compatibility}

We make a final adjustment to our estimates to obtain more robust levels of adult mortality. We control the estimates by comparing the number of deaths in each Brazilian state to the sum of deaths we obtain by adding up the deaths estimated in each of the mesoregions that belong to that particular state ${ }^{1}$. For each state, we add up the number of deaths in each mesoregion and compare to the number of deaths in each state. In the situations where there is a difference in the summation of mesoregions to states, we adjust the deaths in each small area by the same factor to make total number of deaths equals to the state level.

\subsubsection{Spatio-temporal analyses}

We apply two approaches to study the spatial evolution of adult mortality. First, we use cluster analyses based on latent class models to determine spatial cluster across mesoregions. Second, we use spatial autocorrelation measures to determine the hotspot and outliers of adult mortality across country.

Latent class cluster is a group of clusters that falls in the family of mixture likelihood approach to clustering (McLachlan and Basford 1988; Everitt 1993), model-based clustering (Banfield and Raftery 1993; Bensmail et. al. 1997; Fraley and Raftery 1998), mixture-model clustering (Jorgensen and Hunt 1996; McLachlan et al. 1999), Bayesian classification (Cheeseman and Stutz 1995),

\footnotetext{
${ }^{1}$ We have encountered very small differences between both estimates in the majority of the cases; the exception is the Federal State of Maranhão, an area well known for having the worse data quality of the country (Lima and Queiroz, 2014). There, we find differences over $10 \%$.
} 
unsupervised learning (McLachlan and Peel 1996), and latent class cluster analysis (Vermunt and Magidson 2000).

This approach differs from standard cluster analysis techniques, since the class latent clustering uses a model-based clustering approach (Vermunt \& Magidson 2002). Classical clusters methods, such as k-means, are commonly based on intuitively reasonable procedures (Everitt et al. 2011), but it is difficult to make decisions based on the best distance method to use and the estimation procedure for number of clusters. The latent class cluster applies statistical models for the population under study. It assumes that the population consists of many subpopulations or clusters and the latter have different multivariate probability density functions, defined by a finite mixture of underlying probability distributions (Everitt et al. 2011; Vermunt \& Magidson 2002). This finite mixture modelling is a form of latent variable analysis, and each "subpopulation" being a latent categorical variable and the latent classes being described by the different components of the mixture density.

The allocation of objects to clusters should be optimal based on some criteria. These criteria involve minimizing the within-cluster variation and/or maximizing the between-cluster variation (Vermunt \& Magidson 2002). The advantage of using a statistical model is that the choice of the cluster criterion is less arbitrary. In addition, latent class clustering is very flexible in the sense that both simple and complicated distributional forms can be used for the observed variables within clusters (Everitt et al. 2011; Vermunt \& Magidson, 2002).

In the second part, we use Moran Index to analyze the spatial pattern at the variation of the adult mortality probability across Brazilian's mesoregions. Moran Index is a correlation coefficient that measures the linear relationship between same variables' values across of the neighbor's areas, and so it receives the prefix auto and becomes a spatial autocorrelation index (Bailey e Gatrell, 1995; Bivand et al, 2008). 
Spatial autocorrelation can be global or local (Ward and Gleditsch, 2007; Anselin, 1995). When using global autocorrelation, we are interested in analyzing the global spatial pattern that allows us to analyze whether the observed pattern is at random or not (Anselin, 1995). For example, if the variation of the adult mortality probability is higher in some sub-national areas than others, and if between them there is a well-defined spatial gradient. With the local autocorrelation we are interested in measuring relationships between closest neighbors areas. In several situations, it could be very important analyzing both indexes, local and global one, simultaneously. Hence, the local autocorrelation makes possible identifying local spatial clusters, or hotspots. Moreover, they may be used to assess the influence of individual locations on the magnitude of the global statistic and to identifiy "outliers," (Anselin, 1993). The test of significance is built with pseudo-distributions references, generated from simulations (Bailey e Gatrell, 1995; Bivand, et al, 2008).

\section{Results}

\subsection{Evolution of completeness of death counts and adult mortality in Brazil}

Before moving to the results of the evolution of completeness of death counts coverage across regions in Brazil, we show the observed and smoothed age-specific mortality rates for males in 1980/1991 for two selected regions, after applying the first step of our proposed method. Figure 1 shows observed and smoothed mortality rates for Amazonas, region with worse death data quality, and Santa Catarina, a region with better death data quality. The left panel shows the smoothed rates and the right panel shows the observed data. The standardization technique smoothed rates by keeping constant, across the ages, the differences on the levels of mortality rates between mesoregions. In Santa Catarina, there is no significant difference on the level of mortality rates between its mesoregions. Moreover, the observed mortality rates for mesoregions in Santa Catarina are more stable compared to the mortality age profile observed in Amazonas. For each region of Amazonas, 
we see that observed rates are very unstable and some age groups have unexpected high or low mortality rates, also we observed some age groups without any recorded death. The application of the standardization procedure allows us to obtain reasonable age profiles to study spatial and temporal variation in the country. The results of the procedure provide evidence that this simple approach is a good way to smooth mortality rates at the local levels for countries with poor data quality. There are alternatives to smooth mortality rates for small-areas (Gonzaga and Schmmertman, 2016; Camarda, 2012). Both methods use a combination of statistical and relational demographic models. We argue that our results are very robust and easy to replicate for different scenarios. They demand less data than the other proposed methods, it is independent of a model life-table, it is not related to a standard population and it is very simple to apply and replicate.

\section{Figure 1: Observed and smoothed age-specific mortality rates according to selected mesoregions in Brazil, males, 1980-91}
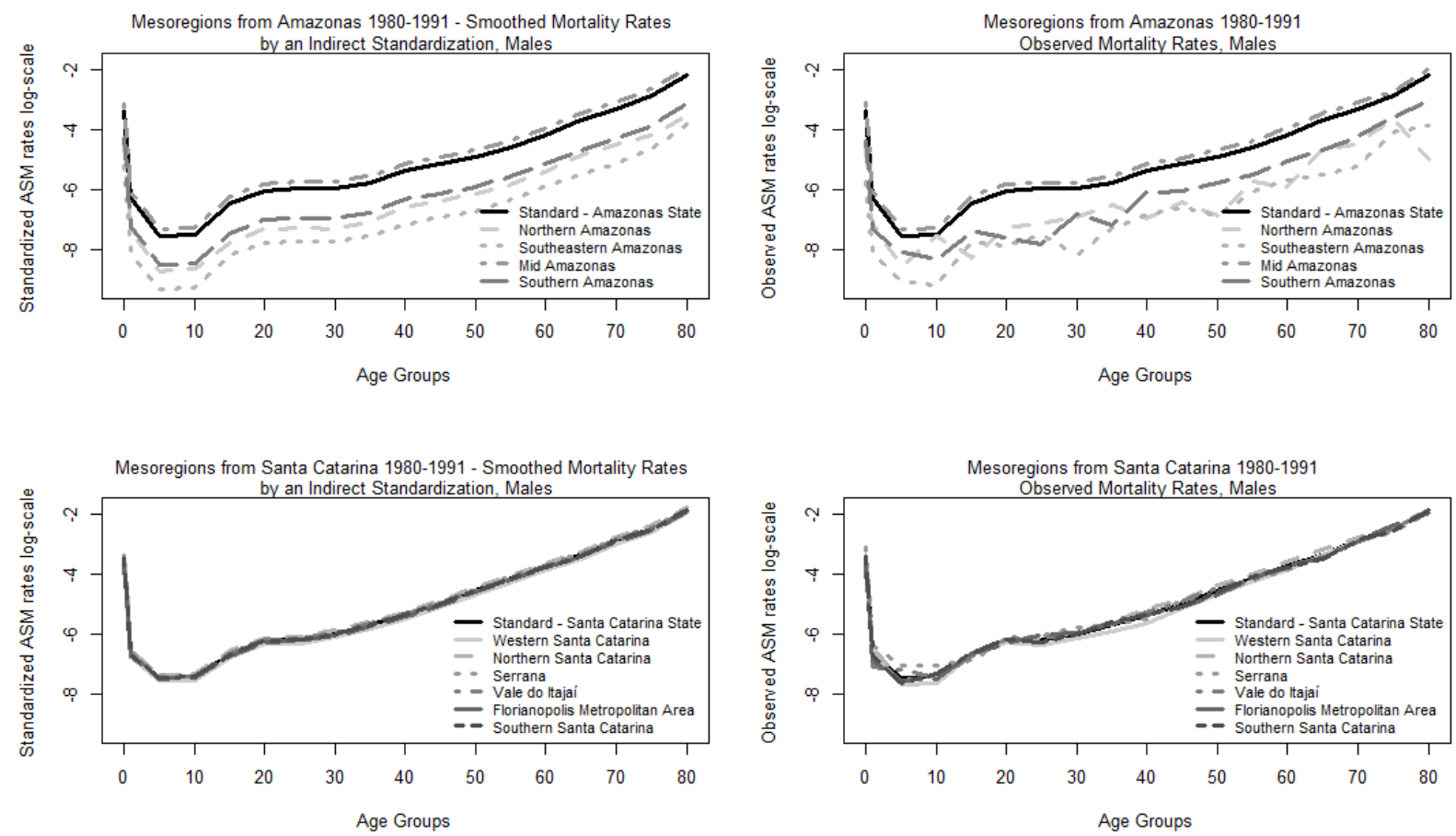

Source: IBGE (1980, 1991 and 2000) and DATASUS (2015). 
Table 1 and Table 2 shows descriptive statistics for the completeness of death counts coverage and adult mortality (45q15) for females and males, respectively, from 1980 to 2010 in Brazil. In recent decades, the quality of mortality data in Brazil has shown considerable progress, but with large regional variability. We observe that states in the south and southeast regions have records of $100 \%$ of deaths in the most recent year, for both sexes. Some states in the northeast and north regions present lower quality of information, but they have shown recent significant advances compared to the earlier periods. In 2010, all states in the south and southeast regions, as well as some in the northeast and Midwest regions, had complete coverage of the death registry. In addition, there was great progress in the quality of mortality information in poorer states in the northeast and north regions, especially those that had the worst record quality in previous periods. We now focus our discussion using maps and the regional variation, but summary statistics are very important to provide a general overview of changes in the country. 
Table 1 - Completeness of Death Counts and Adult Mortality Rates, Females, Brazil and regions, 1980-2010

\begin{tabular}{|c|c|c|c|c|c|c|}
\hline & & ompleteness & & & $45 q 15$ & \\
\hline Brazil & 1980-91 & 1991-00 & 2000-10 & 1980-91 & 1991-00 & 2000-10 \\
\hline Mean & .8367 & .8741 & .8668 & .1313 & .1147 & .1080 \\
\hline Minimum & .11 & .23 & .26 & .0526 & .048 & .0801 \\
\hline Maximum & 1 & 1 & 1 & .2404 & .1977 & .1899 \\
\hline Total of Areas & 137 & 137 & 137 & 137 & 137 & 137 \\
\hline North & 1980-91 & 1991-00 & 2000-10 & 1980-91 & 1991-00 & 2000-10 \\
\hline Mean & .6415 & .76 & .76 & .1385 & .1106 & .1135 \\
\hline Minimum & .11 & .23 & .26 & .0681 & .0480 & .0801 \\
\hline Maximum & 1 & 1 & 1 & .2404 & .1977 & .1899 \\
\hline Total of Areas & 20 & 20 & 20 & 20 & 20 & 20 \\
\hline Northeast & 1980-91 & 1991-00 & 2000-10 & 1980-91 & 1991-00 & 2000-10 \\
\hline Mean & .7466 & .8004 & .7876 & .1085 & .1025 & .1060 \\
\hline Minimum & .30 & .41 & .48 & .0526 & .0744 & .0892 \\
\hline Maximum & 1 & 1 & 1 & .1941 & .1584 & .1510 \\
\hline Total of Areas & 42 & 42 & 42 & 42 & 42 & 42 \\
\hline Mid-West & 1980-91 & 1991-00 & 2000-10 & 1980-91 & 1991-00 & 2000-10 \\
\hline Mean & .8086 & .9233 & .9013 & .1419 & .1200 & .1098 \\
\hline Minimum & .45 & .58 & .73 & .0998 & .0903 & .0924 \\
\hline Maximum & 1 & 1 & 1 & .2222 & .1906 & .1255 \\
\hline Total of Areas & 15 & 15 & 15 & 15 & 15 & 15 \\
\hline South & 1980-91 & 1991-00 & 2000-10 & 1980-91 & 1991-00 & $2000-10$ \\
\hline Mean & .9782 & .9560 & .9543 & .1353 & .1192 & .1050 \\
\hline Minimum & .88 & .78 & .78 & .1074 & .0992 & .0898 \\
\hline Maximum & 1 & 1 & 1 & .1674 & .1437 & .1226 \\
\hline Total of Areas & 23 & 23 & 23 & 23 & 23 & 23 \\
\hline Southeast & 1980-91 & 1991-00 & 2000-10 & 1980-91 & 1991-00 & 2000-10 \\
\hline Mean & .9678 & .9486 & .9486 & .1464 & .1259 & .1084 \\
\hline Minimum & .83 & .83 & .78 & .1129 & .0943 & .0874 \\
\hline Maximum & 1 & 1 & 1 & .1815 & .1567 & .1393 \\
\hline Total of Areas & 37 & 37 & 37 & 37 & 37 & 37 \\
\hline
\end{tabular}


Table 2 - Completeness of Death Counts and Adult Mortality Rates, Males, Brazil and regions, 1980-2010

\begin{tabular}{|c|c|c|c|c|c|c|}
\hline & \multicolumn{3}{|c|}{ Completeness } & \multicolumn{3}{|c|}{$45 q 15$} \\
\hline Brazil & 1980-91 & 1991-00 & $2000-10$ & 1980-91 & 1991-00 & $2000-10$ \\
\hline Mean & .8317 & .8855 & .8854 & .2382 & .2168 & .2100 \\
\hline Minimum & .07 & .19 & .36 & .1126 & .1052 & .1449 \\
\hline Maximum & 1 & 1 & 1 & .6057 & .3493 & .2685 \\
\hline Total of Areas & 137 & 137 & 137 & 137 & 137 & 137 \\
\hline North & 1980-91 & 1991-00 & $2000-10$ & 1980-91 & 1991-00 & $2000-10$ \\
\hline Mean & .6055 & .7535 & .7460 & .2653 & .2006 & .2085 \\
\hline Minimum & .07 & .19 & .36 & .1160 & .1052 & .1449 \\
\hline Maximum & 1 & 1 & 1 & .6057 & .3137 & .2668 \\
\hline Total of Areas & 20 & 20 & 20 & 20 & 20 & 20 \\
\hline Northeast & 1980-91 & 1991-00 & 2000-10 & 1980-91 & 1991-00 & 2000-10 \\
\hline Mean & .7790 & .8497 & .8419 & .1904 & .1877 & .2018 \\
\hline Minimum & .36 & .54 & .59 & .1126 & .1352 & .1571 \\
\hline Maximum & 1 & 1 & 1 & .3135 & .3019 & .2673 \\
\hline Total of Areas & 42 & 42 & 42 & 42 & 42 & 42 \\
\hline Mid-West & 1980-91 & 1991-00 & 2000-10 & 1980-91 & 1991-00 & 2000-10 \\
\hline Mean & .75 & .90 & .898 & .2575 & .2286 & .2169 \\
\hline Minimum & .38 & .60 & .73 & .1983 & .1758 & .1845 \\
\hline Maximum & 1 & 1 & 1 & .3780 & .3493 & .2425 \\
\hline Total of Areas & 15 & 15 & 15 & 15 & 15 & 15 \\
\hline South & 1980-91 & 1991-00 & 2000-10 & 1980-91 & 1991-00 & 2000-10 \\
\hline Mean & .9843 & .9652 & .9660 & .2414 & .2253 & .2055 \\
\hline Minimum & .88 & .80 & .83 & .1995 & .1922 & .1752 \\
\hline Maximum & 1 & 1 & 1 & .2725 & .2609 & .2305 \\
\hline Total of Areas & 23 & 23 & 23 & 23 & 23 & 23 \\
\hline Southeast & 1980-91 & 1991-00 & 2000-10 & 1980-91 & 1991-00 & 2000-10 \\
\hline Mean & .9521 & .9418 & .9660 & .2681 & .2484 & .2202 \\
\hline Minimum & .79 & .80 & .79 & .2065 & .1705 & .1756 \\
\hline Maximum & 1 & 1 & 1 & .3197 & .3049 & .2685 \\
\hline Total of Areas & 37 & 37 & 37 & 37 & 37 & 37 \\
\hline
\end{tabular}

Source: DATASUS, 2012 and Population Censuses $(1980,1991,2000,2010)$.

Figure 2 shows the spatial evolution of completeness of death counts in Brazil by sex and mesoregions from 1980 to 2010 . We show the estimates based on the average of the three methods applied to the data. The estimates show that completeness of death counts is improving in Brazil 
overtime, for the country we find that completeness of death counts coverage increased from about $80 \%$ in $1980-1991$ to $95 \%$ in $2000-2010$., The South and Southeast regions have better coverage of deaths counts than other regions in 1980 , reaching almost $90 \%$ and improving to close to $100 \%$ in the more recent years. In the North and Northern parts of the country, completeness, is improving rapidly over the last decades (from $60 \%$ to $90 \%$ in the period), but we can still find areas showing less than $90 \%$ completeness in the most recent years. For example, in Piaui, one of the poorest states in Brazil, completeness improved from $59 \%$ in $1980-1991$ to $90 \%$ in $2000-2010$. This is partially explained by investments from the Ministry of Health in collecting death counts (Paes and Albuquerque, 1999; Paes, 2005).

In 1980-1991, regions with reasonable and very good data quality are located in the southern part of the country whereas most of northern parts are characterized by very poor data quality. In 2000-2010, our estimates show a clear improvement in the quality of data for the whole country, although there are still some areas that need improvements over the next few years. In the Northeast, the closest areas of the states' capitals ${ }^{2}$ have a good coverage during all the period. Males in general have higher coverage of deaths counts than females, mainly on the North Brazil, but the difference seems to decrease on the last decade. One hypothesis would be because the mortality for external cause greatly increased on the last decade, especially among men, and external causes of deaths are better registered than others (Queiroz, et.al, 2017; Moura, et.al, 2015; Lima and Queiroz, 2014; Waiselfisz, 2013).

\footnotetext{
${ }^{2}$ In Brazil, all the States's Capitals in Northeast region are located on the seacoast areas.
} 
Figure 2: Evolution of completeness of deaths counts by sex and Mesoregions in Brazil, 19802010
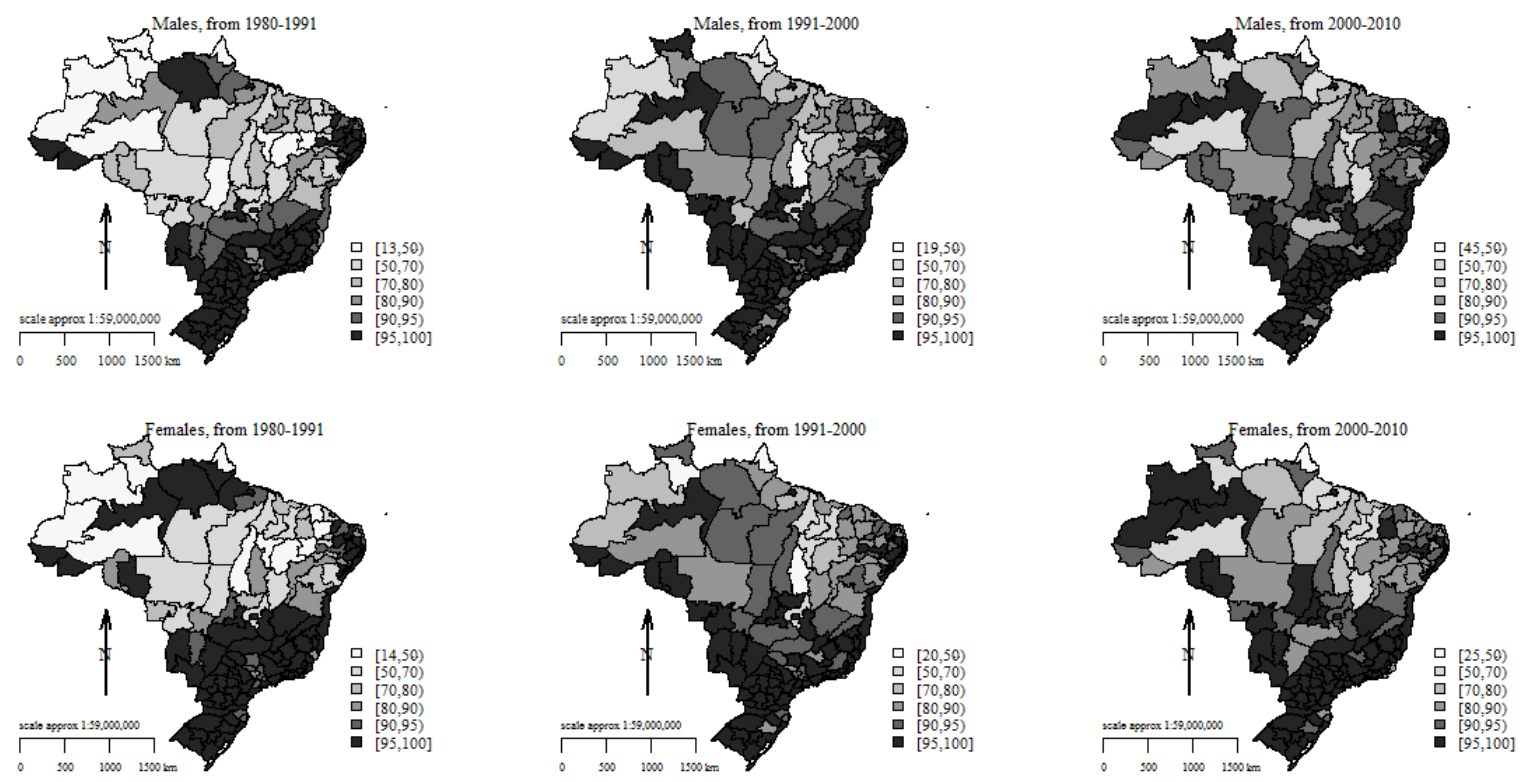

Source: IBGE (1980, 1991 and 2000) and DATASUS (2015).

Figure 3 shows the evolution of adult mortality, measured by the probability of death between ages 15 and 60 (45q15), by sex and mesoregions in Brazil from 1980 to 2010. The main feature is the decline in adult mortality for both sexes and all regions over the period. Although the pattern of decline seems to be similar between males and females, male mortality remains higher in some areas, especially on the Southeast, costal Northeast and few Northern areas. In these areas, the risk of dying between the ages of 15 to 60 is around 0.25 . This higher male mortality may be a consequence on the increase of violence rates on those areas (Moura, et..al, 2015; Waiselfisz, 2013; Reichenheim et al, 2011). While in the Southeast areas, the violence rates have been kept high, on the Northeast it increased relatively in the last two decade (Waiselfisz, 2013; de Andrade and Diniz, 2013; Carvalho, et.al, 2012; Pereira and Queiroz, 2016).

In most Northern and Northeastern areas, we observe a slowdown in the pace of mortality decline for both sexes. There are two possible explanation. The first one would be due the fact that on the first decade there was a big decline, resulting in mortality level smallest to start point for the 
second decade. The second one is related to the increasing risks of death by external causes in Northeast and North areas of the county (Borges, 2017; Waiselfisz, 2013).

Figure 3: Evolution of adult mortality (45q15) by sex and mesoregions in Brail, 1980-2010
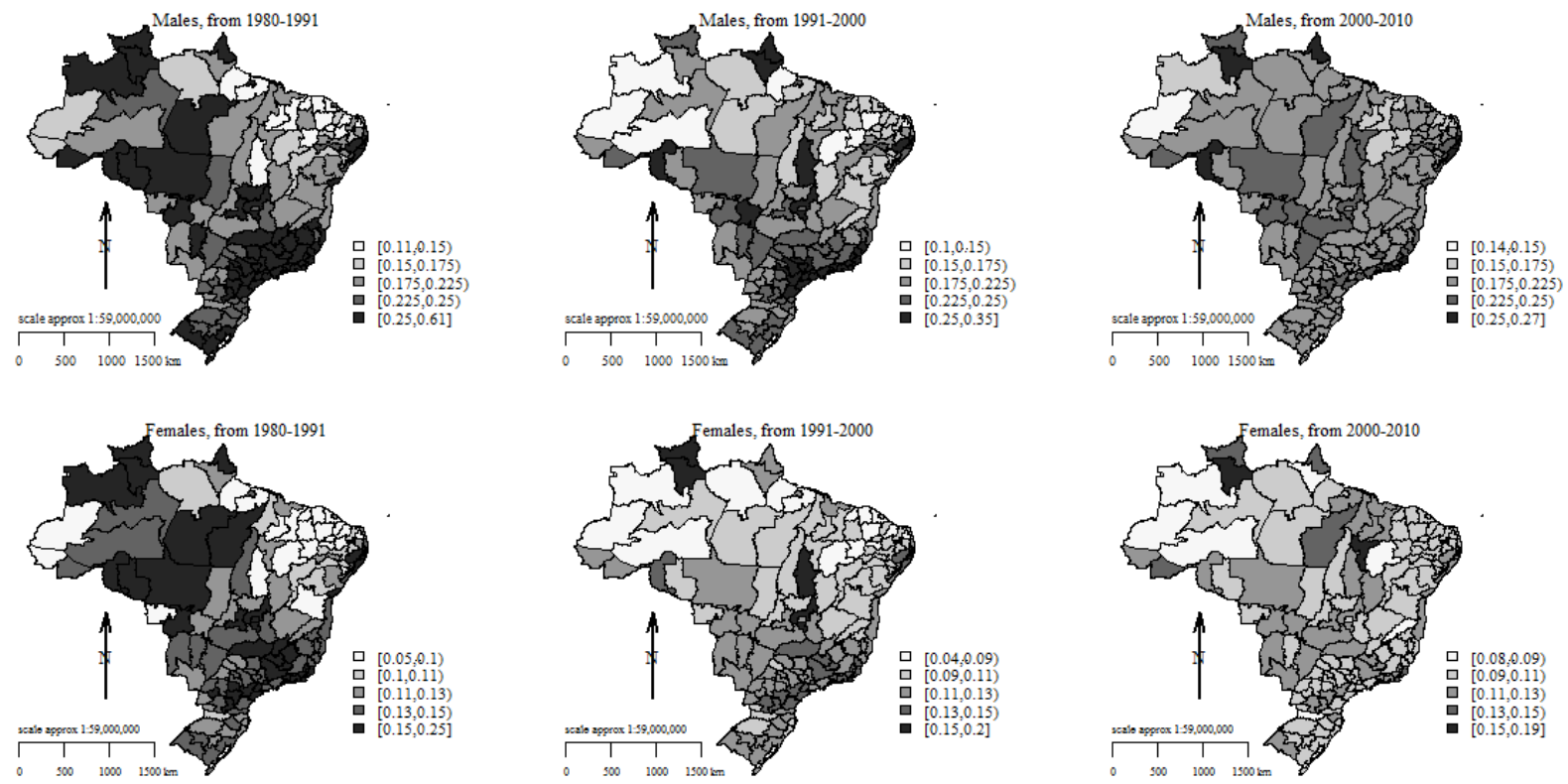

Source: IBGE (1980, 1991 and 2000) and DATASUS (2015).

Adult mortality, 45q15, differs substantially across regions in Brazil during the last three decades. We find that most of the regions with high mortality levels in 1980-1991 are the same with high levels of mortality in the most recent period. Similar trends are observed for males and females. Figure 4 plots the relationship between probability of death between ages 15 and 60 in 1980-1991 and the same measure in 2000-2010 for males and females. The $\mathrm{x}$-axis show the estimates of $45 \mathrm{q} 15$ for the most recent period and the y-axis the same measure for 1980-1991. We find that regions with high probability of deaths in the 1980s are still the regions with high levels of mortality in the most recent periods. For males, the correlation coefficient has increased (from 0.56 to 0.76 ) significantly from 1980 to 2010. Among females, we also verify a positive relationship, but somewhat lower than males (correlation coefficient changed from 0.59 to 0.66 from 1980 to 2010). 
Figure 4: Relationship between adult mortality probabilities in two periods, Males, Brazil $(\mathbf{1 9 8 0} / 1991$ and 2000/2010)

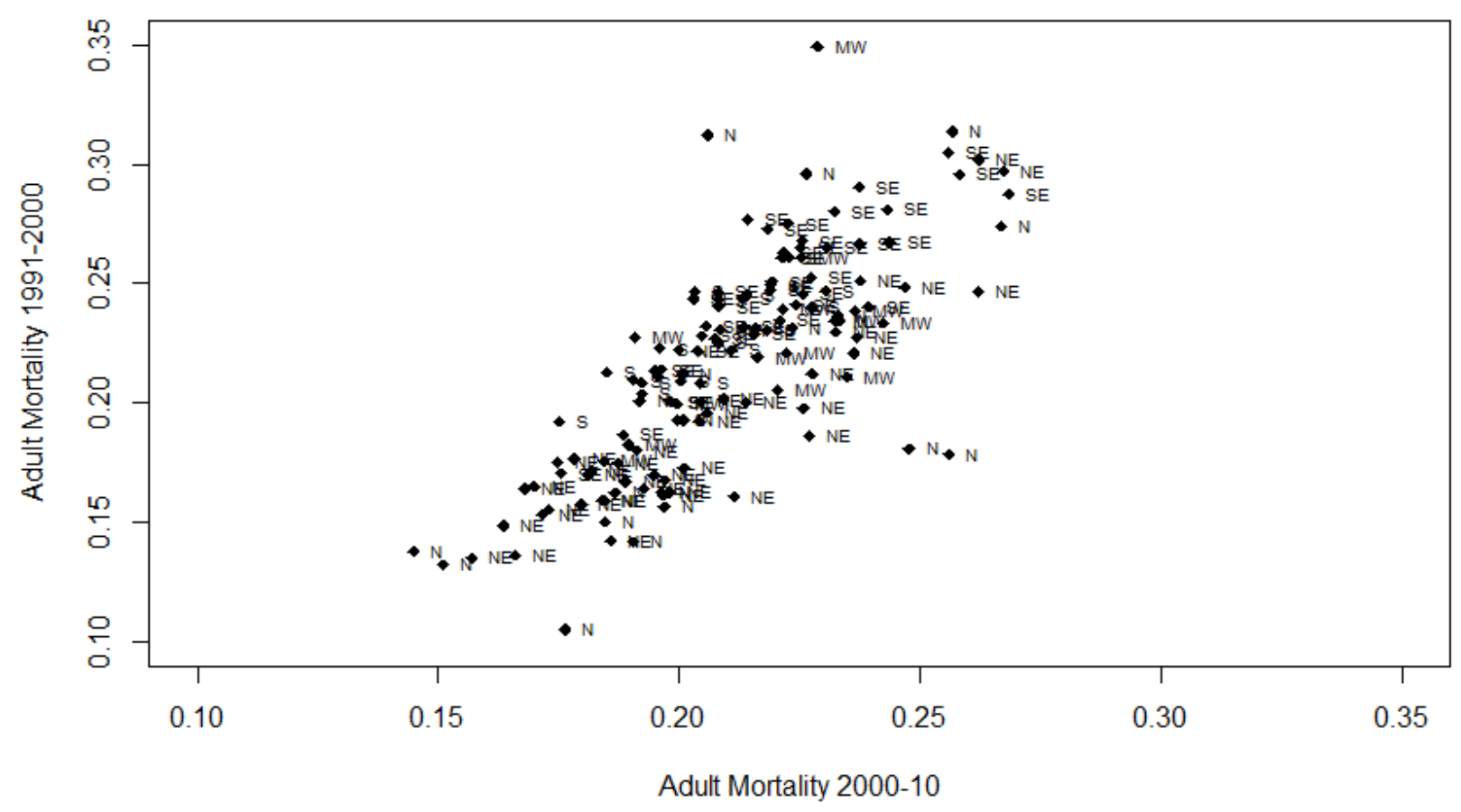

Source: IBGE (1980, 1991 and 2000) and DATASUS (2015).

The divergence and the slow convergence process in adult mortality in Brazil in the recent years reflects the slow rhythm of mortality decline in some regions of the country (Borges, 2017). In general, regions with high mortality levels in 1980 show slower decline in adult mortality and have higher levels in the more recent periods. One way to look at this trend is to estimate the variation in intercensal adult mortality probabilities and analyze the variation spatially. We focus on this analysis in the next section.

\subsection{Spatial analysis of adult mortality patterns}

In this section, we focus on the spatial analysis of adult mortality patterns. This analysis helps to further understand previous discussion and help us to shine some light on understanding mortality dynamics across time and space in Brazil. In order to do that, we take into account centroids from the 
mesoregions to perform our cluster estimates, in addition to the variation in probabilities of death. Centroids are used as control variables (spatial) to the model.

In the first period (1980-1991 to 1991-2000), for males, we identify three spatial clusters. The first cluster covers the whole North and parts of Northeast and Mid-West regions. This is a very heterogeneous clustering composed by mesoregions with reductions (36.4\%), unchanged variability $(33.3 \%)$ and increase in adult probability of death $(30.3 \%)$ through time. The second cluster (Northeastern) is composed by many mesoregions that has almost not changed the risk of mortality (51.5\%), and $48.5 \%$ of the areas that observed an increase in mortality from 1980-1991 to 1991-2000. The third cluster has predominantly (93\%) mesoregions with no changes in the probability of death. Furthermore, we also observed in the last cluster, respectively, $4 \%$ and $3 \%$ of the mesoregions with decrease and increase in adult mortality probabilities. In this cluster, we find the most developed areas of the country, which involves the whole South, Southeast and some parts of Mid-West.

For females, we find a very similar spatial pattern of variation (composed by three clusters) with slightly differences as compared to the men. Therefore, we can conclude that for the first twenty years of mortality change, the entire Northeast and some parts of North the adult mortality risks have increased, although in the most developed parts of the country it has almost not changed their levels.

In the second period (1991-2000 to 2000-2010), we identify additional clusters of mortality variation. For males, we identify five different clusters. First, we find the same the Mid-West and Northern cluster. We also notice that most areas presented no changes $(35.9 \%)$ or present an increase (38.5\%) in adult mortality. The Northeastern cluster presents also more areas with increased mortality risks $(75 \%)$. It is important to mention that in a specific cluster not all mesoregions have only increased or decreased their probabilities of death during the considered period. For this reason, we 
have described it according the amount the areas that have experienced reduction or increases in the risk of mortality.

Our analysis divided the Southeast into two spatial clusters. In the upper Southeastern region, $74 \%$ of areas observed a reduction in mortality and $26 \%$ had no significant changes In the low Southeastern cluster $100 \%$ of its mesoregions observe mortality decline. The last spatial chunk has a similar profile to the upper Southeastern, with $80 \%$ presenting decrease and $20 \%$ mesoregions with no change in the variations of ${ }_{45} \mathrm{q}_{15}$ from $1991-2000$ to $2000-2010$.

For females, we identify a fourth spatial cluster. With few exceptions, the spatial profile does not changed much compared to males. The Northern and high Mid-West cluster is still the most heterogeneous one, with slightly predominance reduction (33.3\%) and $41 \%$ mesoregions increasing the adult mortality in the second analysis period. The Northeastern is characterized by mainly increase (53.3\% of the areas) and $37.8 \%$ presenting no change in ${ }_{45} \mathrm{q}_{15}$ variations. The last two clusters present similar pattern in variation in of adult mortality, showing a majority of mesoregions with decreasing adult mortality from $1991-2000$ to $2000-2010$. 
Figure 5: Spatial cluster of variation in males and female adult probability of death between 1980 and 2010 by Mesoregions in Brazil with corrections for underreporting of deaths ${ }^{3}$
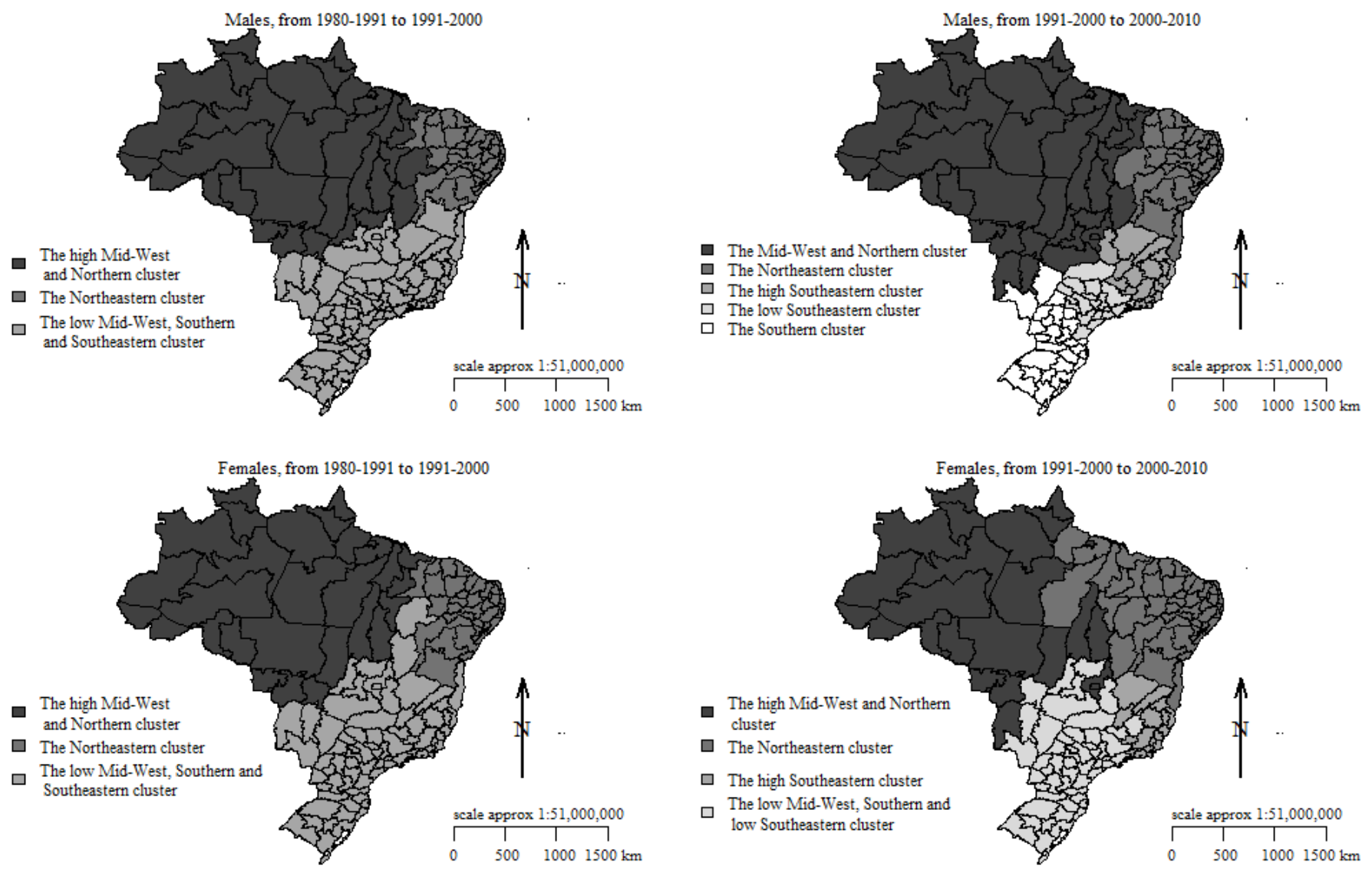

Source: IBGE (1980, 1991 and 2000) and DATASUS (2015).

3 Note: The kind of variation, respectively, decrease, no change and increase in adult mortality.

Males, first period of variation, cluster 1: $36.4 \%, 33.3 \%$ and $30.3 \%$; cluster 2: $0.0 \%, 51.5 \%$ and $48.5 \%$, and cluster 3: $4.2 \%, 93.0 \%$ and $2.8 \%$. Males, second period of variation, cluster 1: $25.6 \%, 35.9 \%$ and $38.5 \%$; cluster 2: $8.3 \%, 16.7 \%$ and $75.0 \%$; cluster 3: $73.7 \%, 26.3 \%$ and $0.0 \%$; cluster $4: 100 \%, 0 \%$ and $0 \%$ and cluster 5: $80 \%$, $20 \%$ and $0 \%$.

Females, first period of variation, cluster 1: $37.9 \%, 34.5 \%$ and $27.6 \%$; cluster 2: $0 \%, 60 \%$ and $40 \%$ and cluster 3: $9.6 \%, 89 \%$ and 1.4\%. Females, second period of variation, cluster 1: $33.3 \%, 25 \%$ and 41.7\%; cluster 2: $8.9 \%$ $37.8 \%$ and $53.3 \%$; cluster 3: $76.5 \%, 23.5 \%$ and $0 \%$ and cluster $4: 80.4 \%, 19.6 \%$ and $0 \%$. 
Even in the second period of analysis, we find comparable results to the previous period. The Northeast and some parts of North the adult mortality risks have increased considerably, although, the most developed parts of the country, especially in the South and the Southeast it has decreased or kept unchanged in the most mesoregions. Probably it indicates that socioeconomic developments might be associated with lesser mortality levels.

\subsection{Spatial analyses on the variation of adult mortality in Brazil}

In the last step, we perform a spatial auto-correlation analysis showing Global and Local Morn Indexes to investigate the variation of the adult mortality by sex and regions between 1980-1991 to 1991-2000 and 1991-2000 to 2000-2010. The presence of spatial clusters of high and low changes in adult mortality (45q15) are assessed using a local indicator of spatial association (LISA), specifically the local Moran's I statistic (Anselin 1995; Cliff and Ord 1975). We are interested in assessing whether relative reduction in adult mortality are randomly distributed or concentrated in particular areas. We find for both males and females, that the Global Index is positive and significant, indicating that the spatial variation in $45 q 15$ is not at random.

Figure 6 shows the behavior of the variation in mortality between 1980-91 and 1991-2000 and between 1991-2000 and 2000-2010. The areas characterized as high-high, are the regions where there was a high variation in mortality in the period. In the low-low areas are the regions where the variation in mortality was low in the period. The areas characterized as outliers are the regions where there was significant heterogeneity in mortality variation in the period. These were the regions where neighboring mesoregions have different behavior with respect to variation in mortality, some with high variation and other low variation.

For the first period, 1980-91 to 1991-2000, results indicate that much of the northern part of the country is characterized by low-low areas. This indicates that during that period, most of the regions in the northern part of the country observed low variation in adult mortality as well as the 
surrounding areas. We also observed that a small group of regions, in the northern part of the northeast region, were characterized by high-high variation. That is, neighboring mesoregions with high variability in adult mortality in the period for both men and women. In the second period of analysis, 1991-2000 to 2000-2010, the homogeneous areas of high variation in adult mortality comprises a set of mesoregions in the north-central portion of the northeastern region, mesoregions in the northeastern semi-arid, and mesoregions in the northern region of Brazil.

We also observed, for males and females, a spatiotemporal pattern in the variation of adult mortality. As pointed before, we can treat this variation as a decline in adult mortality because very few regions of the country observed an increase in mortality during the period of analysis. Results indicated that in much of northern Brazil adult mortality reduction was low in the first period of analysis in several neighboring areas, but this reduction was accentuated in several mesoregions in this part of the country in the second period. In the northeast, there was a similar pattern in the northcentral part of the region. Northeast part of the country, compared to the areas of high-high type in two different periods, show some indication of a concentration of high-high regional spatial pattern of high-high type, in other words, some sort of contagion on the rate of the decline in adult mortality over time in that area. In the southern parts of the country, for both periods, we observed a concentration of low-low pattern. The results are less surprising since most states in the region already had the lowest mortality rates in the country. 
Figure 6: Local and spatial autocorrelation of the variation on the adult mortality probabilities (15q45) by sex and mesoregion, Brazil (1980-1991, 2000-2010)

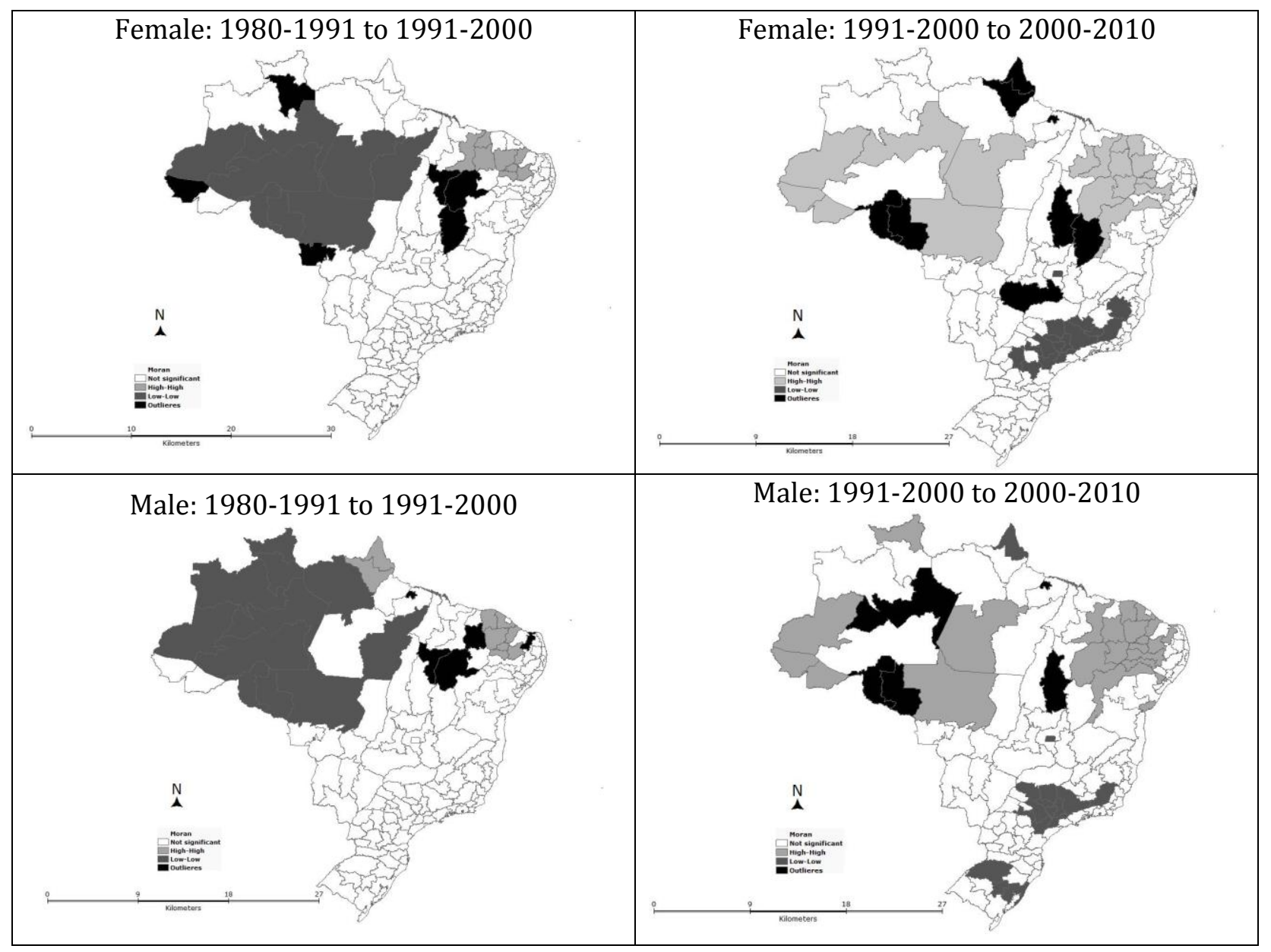

Source: IBGE (1980, 1991 and 2000) and DATASUS (2015).

Despite the overall decline of adult mortality levels throughout time, we also noticed that there is an evolution to homogenization and convergence of $45 \mathrm{q} 15$ across the country. In other words, even with the persistence of hotspots in certain locations of Brazil, adult mortality levels are becoming more alike across mesoregions. This widespread phenomenon is more pronounced among females. It is interesting to observed the convergence in adult mortality across regions of the country between 1980 and 2010. There are still significant differences across regions and we can identify hotspots of high levels of adult mortality in some areas of the countries. These areas are very related to an increase of mortality for external causes affecting young males (Waiselfisz, 2013; Pereira and Queiroz, 2016). 
Reduction in the mortality levels in areas with lower socioeconomic levels might imply better living conditions and overall improvements.

\section{Conclusion}

In this paper, we contribute to the study of adult mortality in Brazil and regions. In general, estimates and analysis of adult mortality in countries are less satisfactory than those of infant and child mortality. This happens to the differences in available data and methods to estimate infant and child mortality compared to adult mortality. Indirect estimates for adult mortality do not seem as robust as methods to estimate infant and child mortality (Hill, Choi and Timaeus, 2005). Thus, it is necessary to provide alternatives to estimate adult mortality and investigate its levels and patterns over time and space.

We proposed a two-step procedure to estimate mortality in small areas when data is defective. We combine standardization techniques to smooth mortality rates in the mesoregions in order to solve problems of random variation. In the second step, we use Death Distribution Methods to estimate completeness of death counts coverage and adult mortality levels for mesoregions in Brazil. With estimates in hand, we investigate patterns of adult mortality across small areas in Brazil, we make use of some spatial statistics techniques.

The results about the evolution of completeness of death counts and adult mortality in Brazil show us remarkable regional differences on the completeness of deaths counts and adult mortality across three last decades. In recent decades, the quality of mortality data in Brazil improved steadily, but with significant regional differences. We find results similar to observed in other studies for larger areas (Paes, 2005; Paes, 2007; Lima and Queiroz, 2014; Queiroz, et.al, 2017). The main advantage of our approach is to use the same method for all periods of analysis and the study of smaller areas. States in the more developed south and southeast regions show levels of completion close to $100 \%$ 
over time, for both sexes. Some states in the less developed northeast and north regions present lower quality of information, but they have shown recent significant advances compared to levels observed in the 1980s. In 2010, all states in the south and southeast regions, as well as some in the northeast and Midwest regions, had complete coverage of the death registry. In addition, there was great progress in the quality of mortality information in poorer states in the northeast and north regions, especially those that had the worst record quality in previous periods.

Northern and Northeastern regions in Brazil show rapidly improvement on the completeness of deaths counts during the last three decades. Areas closest of the states' capitals have higher coverage during all the period on both regions (Paes, 2005; Paes, 2007; Lima and Queiroz, 2014; Queiroz, et.al, 2017) Similar trends are observed to infant and child mortality. Estimations of infant deaths coverage using a procedure called Active Search on the Northeast and Amazon regions (Szwarcwald et al, 2011) showed that the deaths under-reporting on those areas should be lower than the official estimates (IBGE, 2016).

The results show an improvement in health conditions, measured by adult mortality, in the country. However, we observe that the difference in adult mortality by sex has remained almost constant over the period of analysis. The main explanation is the high level of external causes of deaths for males across the country (Pereira and Queiroz, 2016; Malta, et.al, 2017; Ladeira, et.al, 2017). This also helps to explain the very small variation in $45 q 15$ across regions of the country overtime. Overall, we find 45q15 for males above 0.200 for males and around 0.120 for females. The highest probabilities in 2010 are found in Rio de Janeiro, Espírito Santo, Alagoas, and Pernambuco. We also observed that regions with fastest decline in adult mortality are those with highest mortality levels in the earlier periods. Female adult mortality is much lower than that of males, and the difference between sexes remained practically constant between 2000 and 2010 . 
Souza, França and Cavalcante (2017), based on the Burden of Diseases Study, show that on the North and Northeast of the country the burden of diseases is also higher and, in all others regions, there are predominance of some chronic diseases such as cardiovascular, diabetes and obstructive pulmonary disease. The mental disorders, especially depression, homicides and traffic accidents are also higher and represent a huge public health problem (Borges, 2017; Waiselfisz, 2013).

The spatial-temporal analyses show us some remarkable changes on adult mortality across Brazilian regions over the three last decades. A spatial cluster and the analysis spatial statistics of the variation on mortality probabilities by sex and mesoregions of Brazil show us that between 1980 and 1991 the adult mortality increases homogeneously in almost North and in some parts of the Northeast regions of the country. On the last period of our analyses (between 2000 and 2010) one can see that the increase on adult mortality was more persistent on the Northeast region, mainly for males. According to Waiselfisz (2013) the homicide deaths in the Northeast increased $12.2 \%$ for whites and 96.7\% for blacks between 2002 and 2010. In the same period, in the southeast these deaths decreased $50.8 \%$ and $30.1 \%$, respectively, in whites and blacks.

On the South and Southeast of Brazil the reductions on adult mortality were persistent for both sex and both periods of analyzes. The scenarios of increasing adult mortality on the North and Northeast and reductions on the South and Southeast of the country is consistent with changes on the age-pattern of the causes of deaths. The analysis suggests that efforts made by central and local governments to improve data quality in Brazil (Borges, 2017; Frias, et.al, 2017) are showing signs of success, and that they will allow a better understanding of the dynamics of health and mortality transition in Brazil. It is clear, however, that more investments are necessary in some parts of the country that are still lagging behind in this area. It is important that there be continuous study and evaluation of data quality, especially for small areas and investments for all administrative levels to improve health information in Brazil (Mello-Jorge, Laurenti and Gotlieb, 2010). 


\section{References}

AbouZahr, C., \& Boerma, T. (2005). Health information systems: the foundations of public health. Bulletin of the World Health Organization, 83(8), 578-583.

AbouZahr, C., De Savigny, D., Mikkelsen, L., Setel, P. W., Lozano, R., \& Lopez, A. D. (2015). Towards universal civil registration and vital statistics systems: the time is now. The Lancet, 386(10001), 1407-1418.

Anselin, L. (1993). The Moran scatterplot as an ESDA tool to assess local instability in spatial association. Morgantown, WV: Regional Research Institute, West Virginia University.

Anselin, L. (1995). Local indicators of spatial association-LISA. Geographical analysis, 27(2), 93-115.

Assunção, R. M., Schmertmann, C. P., Potter, J. E., \& Cavenaghi, S. M. (2005). Empirical Bayes estimation of demographic schedules for small areas. Demography, 42(3), 537-558.

Bailey, T. C., \& Gatrell, A. C. (1995). Interactive spatial data analysis (Vol. 413). Essex: Longman Scientific \& Technical.

Banfield, J. D., \& Raftery, A. E. (1993). Model-based Gaussian and non-Gaussian clustering. Biometrics, 803-821.

Barufi, A. M., Haddad, E., \& Paez, A. (2012). Infant mortality in Brazil, 1980-2000: A spatial panel data analysis. BMC public health, 12(1), 181.

Bennett, N. G., \& Horiuchi, S. (1981). Estimating the completeness of death registration in a closed population. Population index, 207-221.

Bensmail, H., Celeux, G., Raftery, A. E., \& Robert, C. P. (1997). Inference in model-based cluster analysis. Statistics and Computing, 7(1), 1-10.

Bernardinelli, L., \& Montomoli, C. (1992). Empirical Bayes versus fully Bayesian analysis of geographical variation in disease risk. Statistics in medicine, 11(8), 983-1007.

Bivand, R. S., Pebesma, E. J., Gomez-Rubio, V., \& Pebesma, E. J. (2008). Applied spatial data analysis with $R$ (Vol. 747248717). New York: Springer.

Brass, W. (1975). Methods for estimating fertility and mortality from limited and defective data. Methods for estimating fertility and mortality from limited and defective data.

Borges, G. M. (2017). Health transition in Brazil: regional variations and divergence/convergence in mortality. Cadernos de Saúde Pública, 33(8).

Camarda, C. G. (2012). MortalitySmooth: An R package for smoothing Poisson counts with Psplines. Journal of Statistical Software, 50(1), 1-24.

Carvalho, A. X. Y. D., Silva, G. D. M. D., Almeida Júnior, G. R. D., \& Albuquerque, P. H. M. D. (2012). Taxas bayesianas para o mapeamento de homicídios nos municípios brasileiros. Cad Saude Publica, 1249-1262.

Cavalini, L. T., \& de Leon, A. C. M. P. (2007). Correção de sub-registros de óbitos e proporção de internações por causas mal definidas. Revista de Saúde Pública, 41(1), 85-93. 
Cheeseman, P. \& Stutz, J. (1995). Bayesian classification (AutoClass): Theory and results. In Fayyad, U., Piatesky-Shapiro, G., Smyth, P., \& Uthurusamy, R.(Eds.), Advances in knowledge discovery and data mining, pp. 153-180.

Cliff, A. D., \& Ord, J. K. (1975). Model building and the analysis of spatial pattern in human geography. Journal of the Royal Statistical Society. Series B (Methodological), 37(3), 297-348.

Curtin, L. R., \& Klein, R. J. (1995). Direct standardization (age-adjusted death rates) (No. 6). US Department of Health and Human Services, Public Health Service, Centers for Disease Control and Prevention, National Center for Health Statistics.

de Andrade, L. T., \& Diniz, A. M. A. (2013). A reorganização espacial dos homicídios no Brasil e a tese da interiorização. Revista Brasileira de Estudos de População, 30, 171-191.

Divino, F., Egidi, V., \& Salvatore, M. A. (2009). Geographical mortality patterns in Italy: A Bayesian analysis. Demographic Research, 20, 435-466.

Dorrington, RE. (2014a). General Growth Balance. In Moultrie TA, RE Dorrington, AG Hill, KH Hill, IM Timæus and B Zaba (eds), Tools for Demographic Estimation. http://demographicestimation.iussp.org/content/general-growth-balance.

Dorrington, RE. (2014b). Synthetic extinct generations. In Moultrie TA, RE Dorrington, AG Hill, KH Hill, IM Timæus and B Zaba (eds), Tools for Demographic Estimation. http://demographicestimation.iussp.org/content/synthetic-extinct-generations.

Ehrl, P. (2017). Minimum comparable areas for the period 1872-2010: an aggregation of Brazilian municipalities. Estudos Econômicos (São Paulo), 47(1), 215-229.

Everitt B S., Landau S, Leese M and Stahl D. (2011). Cluster Analysis, 5th Edition. Wiley Series in Probability and Statistics.

Everitt, B.S. (1993), Cluster analysis. London: Edward Arnold.

Fenelon, A. (2013). Geographic divergence in mortality in the United States. Population and development review, 39(4), 611-634.

Fraley, C. and Raftery, A.E. (1998). How many clusters? Which clustering methods? Answers via model-based cluster analysis. Computer Journal, 41, 578-588

França, E; Abreu, DMX; Rao, C.; Lopez, AD. (2008). Evaluation of cause of death statistics for Brazil, 2002-2004. International Journal of Epidemiology, 37(4) 891-901.

Frias, P. G. D., Szwarcwald, C. L., Morais Neto, O. L. D., Leal, M. D. C., Cortez-Escalante, J. J., Souza Junior, P. R. B. D., ... \& Silva Junior, J. B. D. (2017). Use of vital data to estimate mortality indicators in Brazil: from the active search for events to the development of methods. Cadernos de Saúde Pública, 33(3).

Gonzaga, M. R., \& Schmertmann, C. P. (2016). Estimating age-and sex-specific mortality rates for small areas with TOPALS regression: an application to Brazil in 2010. Revista Brasileira de Estudos de População, 33(3), 629-652.

Hill, K. (1987). "Estimating census and death registration completeness." Asian and Pacific Census Forum, 1(3): 8-13,23-24.

Hill, K; Choi, Y; Timaeus, I. (2005). Unconventional approaches to mortality estimation. Demographic Research, v.13, p.281-300. 
Hill, K., You, D., \& Choi, Y. (2009). Death distribution methods for estimating adult mortality: sensitivity analysis with simulated data errors. Demographic Research, 21, 235-254.

IBGE. Tábuas Abreviadas de mortalidade por sexo e idade: Brasil, Grandes Regiões e Unidades da Federação, 2010. Estudos e pesquisas. Informação Demográfica e Socioeconômica, n. 30. Rio de Janeiro: IBGE, 2013. Avaliable at:

http://ibge.gov.br/home/estatistica/populacao/tabuas_abreviadas_mortalidade/2010/default.shtm. Access at: 07/07/2016.

Jorgensen, M., and Hunt, L. (1996), "Mixture Model Clustering of Data Sets with Categorical and Continuous Variables", in Proceedings of the Conference ISIS, Vol. 96), 375-384.

Kibele, E. U., Klüsener, S., \& Scholz, R. D. (2015). Regional mortality disparities in Germany. KZfSS Kölner Zeitschrift für Soziologie und Sozialpsychologie, 67(1), 241-270.

Kulkarni, S. C., Levin-Rector, A., Ezzati, M., \& Murray, C. J. (2011). Falling behind: life expectancy in US counties from 2000 to 2007 in an international context. Population health metrics, 9(1), 16.

Ladeira, R. M., Malta, D. C., Morais Neto, O. L. D., Montenegro, M. D. M. S., Soares Filho, A. M., Vasconcelos, C. H., ... \& Naghavi, M. (2017). Road traffic accidents: Global Burden of Disease study, Brazil and federated units, 1990 and 2015. Revista Brasileira de Epidemiologia, 20, 157-170.

Lima, E. E. C. D., \& Queiroz, B. L. (2014). Evolution of the deaths registry system in Brazil: associations with changes in the mortality profile, under-registration of death counts, and ill-defined causes of death. Cadernos de Saúde Pública, 30(8), 1721-1730.

Luy, M. (2011). A classification of the nature of mortality data underlying the estimates for the 2004 and 2006 United Nations' World Population Prospects. Comparative Population Studies, 35(2).

Malta, D. C., Minayo, M. C. D. S., Soares Filho, A. M., Silva, M. M. A. D., Montenegro, M. D. M. S., Ladeira, R. M., ... \& Naghavi, M. (2017). Mortality and years of life lost by interpersonal violence and self-harm: in Brazil and Brazilian states: analysis of the estimates of the Global Burden of Disease Study, 1990 and 2015. Revista Brasileira de Epidemiologia, 20, 142-156.

Mckinnon, S.A. Municipality-level estimates of child mortality for Brazil: A new approach using Bayesian Statistics. [Dissertation]. The University of Texas at Austin, December, 2010.

McLachlan, G. and Basford, K. (1988), Mixture Models: Inference and Applications to Clustering, New York: Marcel Dekker.

McLachlan, G. J., \& Peel, D. (1996). An algorithm for unsupervised learning via normal mixture models. ISIS: Information, Statistics and Induction in Science, DL Dowe, KB Korb, and JJ Oliver (Eds.), 354-363.

McLachlan, G. J., Peel, D., Basford, K. E., \& Adams, P. (1999). The EMMIX software for the fitting of mixtures of normal and t-components. Journal of Statistical Software, 4(2), 1-14.

Mello Jorge, M. H. P., Laurenti, R., \& Gotlieb, S. L. D. (2010). Avaliação dos sistemas de informação em saúde no Brasil. Cad. Saúde Colet, 18, 07-18.

Ministério da Saúde. Sistema de Informações sobre Mortalidade (SIM) de 1979 a 2010.

Moura EC, Gomes R, Falcão MTC, Schwarz E, Never ACM, Santos W. (2015) Gender inequalities in external cause mortality in Brazil, 2010. Ciênc Saúde Coletiva, 20(3): 779-88 
Murray, CJL; Rajaratnam JK, Marcus J, Laakso T, Lopez AD. (2010) What can we conclude from death registration? Improved methods for evaluating completeness. PLoS Medicine. 13; 7(4)

Paes, N. A. (2005). Avaliação da cobertura dos registros de óbitos dos estados brasileiros em 2000. Revista de Saúde Pública, 39(6), 882-890.

Paes, N. A., \& Albuquerque, M. E. E. (1999). Avaliação da qualidade dos dados populacionais e cobertura dos registros de óbitos para as regiões brasileiras. Rev Saúde Pública, 33(1), 33-43.

Pereira, F. N. A., \& Queiroz, B. L. (2016). Diferenciais de mortalidade jovem no Brasil-a importância dos fatores socioeconômicos dos domicílios e das condições de vida nos municípios e UFs. Cadernos de Saúde Pública, 32(9).

Preston, Samuel, HEUVELINE, P. and GUILLOT, Michel. Demography: Measuring and Modeling Population Processes. Oxford: Blackwell, 2001.

Queiroz, B. L., Freire, F. H. M. D. A., Gonzaga, M. R., \& Lima, E. E. C. D. (2017). Completeness of death-count coverage and adult mortality (45q15) for Brazilian states from 1980 to 2010. Revista Brasileira de Epidemiologia, 20, 21-33.

Ram, U., Jha, P., Gerland, P., Hum, R. J., Rodriguez, P., Suraweera, W., ... \& Gupta, R. (2015). Age-specific and sex-specific adult mortality risk in India in 2014: analysis of 0. 27 million nationally surveyed deaths and demographic estimates from 597 districts. The Lancet Global Health, 3(12), e767-e775.

Reichenheim, M. E., De Souza, E. R., Moraes, C. L., de Mello Jorge, M. H. P., Da Silva, C. M. F. P., \& de Souza Minayo, M. C. (2011). Violence and injuries in Brazil: the effect, progress made, and challenges ahead. The Lancet, 377(9781), 1962-1975.

Ruther, M., Leyk, S., \& Buttenfield, B. (2017). Deriving Small Area Mortality Estimates Using a Probabilistic Reweighting Method. Annals of the American Association of Geographers, 1-16.

Schmertmann, C. P., Potter, J. E., \& Cavenaghi, S. M. (2008). Exploratory analysis of spatial patterns in Brazil's fertility transition. Population Research and Policy Review, 27(1), 1-15.

Schmertmann, C. P., Cavenaghi, S. M., Assunção, R. M., \& Potter, J. E. (2013). Bayes plus Brass: Estimating total fertility for many small areas from sparse census data. Population studies, 67(3), 255-273.

Setel P, MacFarlane SB, Szreter S, Mikkelsen L, Jha P, et al. (2007) Who Counts (1): A scandal of invisibility: making everyone count by counting everyone. Lancet 370: 1569-1577.

Souza, A.; Hill, K and Dal Poz, M. (2010). Sub-national assesment of inequality trends in neonatal and child mortality in Brazil. International Journal for Equity in Health, 9:21.

Souza, M. D. F. M. D., França, E. B., \& Cavalcante, A. (2017). Burden of disease and health situation analysis: results of the Global Burden of Disease (GBD) Brazil network. Revista Brasileira de Epidemiologia, 20, 1-3.

Stephens, A. S., Purdie, S., Yang, B., \& Moore, H. (2013). Life expectancy estimation in small administrative areas with non-uniform population sizes: application to Australian New South Wales local government areas. BMJ open, 3(12), e003710.

Tsimbos, C., Kalogirou, S., \& Verropoulou, G. (2014). Estimating spatial differentials in life expectancy in Greece at local authority level. Population, Space and Place, 20(7), 646-663. 
Vermunt, J. K., \& Magidson, J. (2002). Latent class cluster analysis. Applied latent class analysis, 11, 89-106.

Vermunt, J. K., \& Magisdon, J. (2000). Latent GOLD's User's Guide Statistical. Innovations Inc., Boston.

Waiselfiz, J. J. (2013). Mapa da violência 2013: homicídios e juventude no Brasil.

Wang, H., Schumacher, A. E., Levitz, C. E., Mokdad, A. H., \& Murray, C. J. (2013). Left behind: widening disparities for males and females in US county life expectancy, 1985-2010. Population health metrics, 11(1), 8 .

Ward, M. D., \& Gleditsch, K. S. (2007). An introduction to spatial regression models in the social sciences. Manuscript at http://www. faculty. washington. edu/mdw. Last visited August, 8, 2007. 